\title{
Correction to: CFD research on particle movement and nozzle wear in the abrasive water jet cutting head
}

\section{Zhengrong Qiang $^{1} \cdot$ Meiping $\mathrm{Wu}^{1} \cdot$ Xiaojin Miao $^{1} \cdot$ Rupy Sawhney ${ }^{2}$}

Published online: 1 November 2019

(C) Springer-Verlag London Ltd., part of Springer Nature 2019

Correction to: The International Journal of Advanced Manufacturing Technology, Volume 95, Issue 9-12, pp 4091-4100

https://doi.org/10.1007/s00170-017-1504-6

Author Meiping Wu wmp169@jiangnan.edu.cn should also be declared as the corresponding author of the article https:// doi.org/10.1007/s00170-017-1504-6.

Publisher's note Springer Nature remains neutral with regard to jurisdictional claims in published maps and institutional affiliations.

The online version of the original article can be found at https://doi.org/ 10.1007/s00170-017-1504-6

\section{Zhengrong Qiang}

qiangzhengrong001@ hotmail.com

$\triangle$ Meiping Wu

wmp169@jiangnan.edu.cn

1 School of Mechanical Engineering, Jiangnan University, Wuxi 214122, China

2 School of Industrial and Systems Engineering, University of Tennessee, Knoxville, TN 37996-2315, USA 